\title{
ESTRATÉGIA DE “DESENVOLVIMENTO” BASEADA NA MOBILIZAÇÃO \\ SOCIAL: das promessas à realidade
}

\author{
"DEVELOPMENT" STRATEGIES BASED ON SOCIAL MOBILIZATION: from \\ promises to the reality
}

\section{ESTRATEGIA DE “DESARROLLO” BASADA EN LA MOVILIZACIÓN SOCIAL: de las promesas a la realidad}

\section{Autores:}

Raquel Breitenbach Bacharel em Desenvolvimento Rural e Gestão Agroindustrial, Mestre em Extensão Rural, Doutoranda em Extensão Rural pela Universidade Federal de Santa Maria

\author{
Alexandre da Silva \\ Engenheiro Agrônomo, Mestre em Extensão Rural e Doutorando em Extensão Rural \\ pela Universidade Federal de Santa Maria
}

\begin{abstract}
Resumo
Esse trabalho objetivou analisar um processo de mobilização social, coordenado pela CCGL Cooperativa Central Gaúcha de Leite (Rio Grande do Sul, Brasil), que tinha o objetivo de despertar os agricultores associados às cooperativas formadoras do grupo, para o aumento da produção de leite, com a finalidade de promover o desenvolvimento rural da região. Este estudo teve como delimitação a área de alcance da Cotrijuí (Cooperativa Agropecuária \& Industrial) e como público-alvo os agricultores produtores de leite associados à cooperativa. Descreveram-se, analisaram-se e classificaram-se os métodos e estratégias utilizadas pela cooperativa, bem como se ponderou criticamente os resultados dessa mobilização. Constatouse que os benefícios do processo se distribuíram de modo desigual entre os atores sociais envolvidos, privilegiando principalmente a CCGL, em detrimento dos produtores de leite.
\end{abstract}

Palavras-chave: mobilização social, produção de leite, desenvolvimento.

\begin{abstract}
This study aimed to analyze a process of social mobilization, coordinated by CCGL - Central Cooperative Gaúcha de Leite (Rio Grande do Sul, Brazil), which aimed to arouse the farmers belonging to the cooperatives that forming the group, to increase milk production in order to promote the rural development of the region. This study encompassed the COTRIJUI's (Agricultural \& Industrial Cooperative) operational area and had as target audience the milk farmers associated to the cooperative. The methods and strategies used by the cooperative were described, analyzed and classified, as well as the results of this mobilization were critically pondered. The study concludes that the benefits of this process are unequally distributed among the involved social actors, privileging mainly the processing companies to the detriment of milk producers.
\end{abstract}

Keywords: social mobilization, milk production, development.

\section{Resumen}

Este estudio tuvo como objetivo analizar un proceso de movilización social, coordinado por CCGL - Cooperativa Central Gaucha de Leche (Rio Grande do Sul, Brasil), cuyo objetivo es despertar los agricultores que pertenecen a las cooperativas forman el grupo, para aumentar la producción de leche con el objetivo de promover el desarrollo rural en la región. Este estudio 
fue definir el alcance de la COTRIJUI (Cooperativa Agrícola e Industrial) y como la audiencia de los productores lecheros asociados a la cooperativa. Se describe, analiza y clasifica los métodos y las estrategias utilizadas por la cooperativa, así como la crítica, ponderó los resultados de esta movilización. Se encontró que los benefícios del proceso se distribuyen de manera desigual entre los actores sociales involucrados, centrándose principalmente CCGL a expensas de los productores de leche.

Palabras clave: movilización social, la producción de leche, el desarrollo.

\section{Introdução e Contextualização da Pesquisa}

O meio rural é um campo/objeto de estudo que permite as mais diversas análises, compostas por um variado número de enfoques, tais como: econômico, social, ambiental, cultural, antropológico, saúde, ações de mobilizações sociais, etc. A maioria das pesquisas não consegue, pela limitação de tempo, recursos, profissionais multidisciplinares, etc. englobar todos os fatores necessários para explicar um fenômeno por completo. Recentemente um número grande de pesquisadores se dedica ao estudo de experiências de desenvolvimento rural ou formas de intervir numa realidade para que esse desenvolvimento ocorra.

Porém, o termo desenvolvimento sofreu e ainda vem sofrendo transformações no seu significado e nas metodologias utilizadas para seu alcance. Inicialmente era considerado como sinônimo de crescimento econômico, posteriormente ocorre a inclusão de outras variáveis a serem consideradas, como as questões culturais, sociais e ambientais. Por ocasião de sua difusão nas pautas sociopolíticas e econômicas mundiais, no contexto pós II guerra mundial, de guerra fria e num cenário que buscava ser pós-colonial, foi considerado como sinônimo de crescimento econômico, tendo no PIB/per capita seu principal indicador. Esta concepção de desenvolvimento, baseada na industrialização, urbanização e burocratização, sofreu severas críticas pelos seus "efeitos indesejados": deterioração ambiental, concentração urbana, desertificação rural e fracasso nas tentativas de reduzir as desigualdades sócio-econômicas (BREITENBACH et. al., 2009).

Tais críticas deram margem à urgência de se ultrapassar a noção de desenvolvimento etnocêntrica, conservadora e economicista ${ }^{1}$ que vinha tendo preeminência nas reflexões e ações relativas ao tema (SOUZA, 1996; 1997; GUERRERO, 1996). Assim, a inclusão e relevância de outras variáveis a serem consideradas nas abordagens sobre o desenvolvimento, como as questões culturais, sociais e ambientais, passam a ser defendidas e problematizadas pela literatura. Passa-se, inclusive, a se defender que o desenvolvimento deve ser uma elaboração própria de cada realidade e cultura, em que um único modelo não pode ser aceito como dado, muito menos imposto de uma cultura ou de uma sociedade a outra (ESCOBAR, 1995; SACHS,1995;TUCKER, 1996).

Dentre as estratégias de desenvolvimento rural se nota que a Mobilização Social (MS) é muito utilizada. Esta pode ser compreendida como embates coletivos pela (re)definição de

\footnotetext{
${ }^{1}$ Conforme Quijano (2005), essa noção decorre da culminação de um processo que começou com a constituição da América e do capitalismo colonial moderno e eurocentrado como um novo padrão de poder mundial. Implica, conseqüentemente, num elemento de colonialidade no padrão de poder hoje hegemônico. E, Tévoédjrè (2002) ainda assevera que a confiança, que temos depositado em certos raciocínios econômicos, os quais difundiram em todo o mundo teoremas e leis ainda não demonstrados, nos levou a becos sem saída. Assim aconteceu, por exemplo, com as teses relativas as monoculturas dos países da "periferia", que permitem aos "países-centro" dispor com segurança de produtos diferenciados e complementares, mas que deixam famintos aqueles que acreditaram na troca compensatória".
} 
padrões culturais e normativos, busca pela participação dos sujeitos em debates públicos, por obter esforços convocatórios, ou seja, ações que possibilitem a inclusão de sujeitos em suas principais questões, criando mecanismos que propiciem a participação (MAFRA, 2006). Também se entende por MS:

[...] a reunião de sujeitos que definem objetivos e compartilham sentimentos, conhecimentos e responsabilidades para a transformação de uma dada realidade, movidos por um acordo em relação à determinada causa de interesse público. (HENRIQUES, BRAGA e MAFRA apud MAFRA 2006).

Com esse trabalho se objetivou analisar criticamente um processo de mobilização social, coordenado pela CCGL (Cooperativa Central Gaúcha de Leite) na região noroeste do estado do Rio Grande do Sul. Esta mobilização teve como objetivo despertar os agricultores da região de alcance e associados às cooperativas formadoras do grupo CCGL, para o aumento da produção de leite in natura, aumentando assim a oferta de matéria-prima para a empresa. Este estudo teve como delimitação a área de alcance da Cotrijuí (Cooperativa Agropecuária \& Industrial), conforme demonstrado na Figura 1, uma das cooperativas que compõe a CCGL, e como público-alvo os agricultores produtores de leite associados à cooperativa.

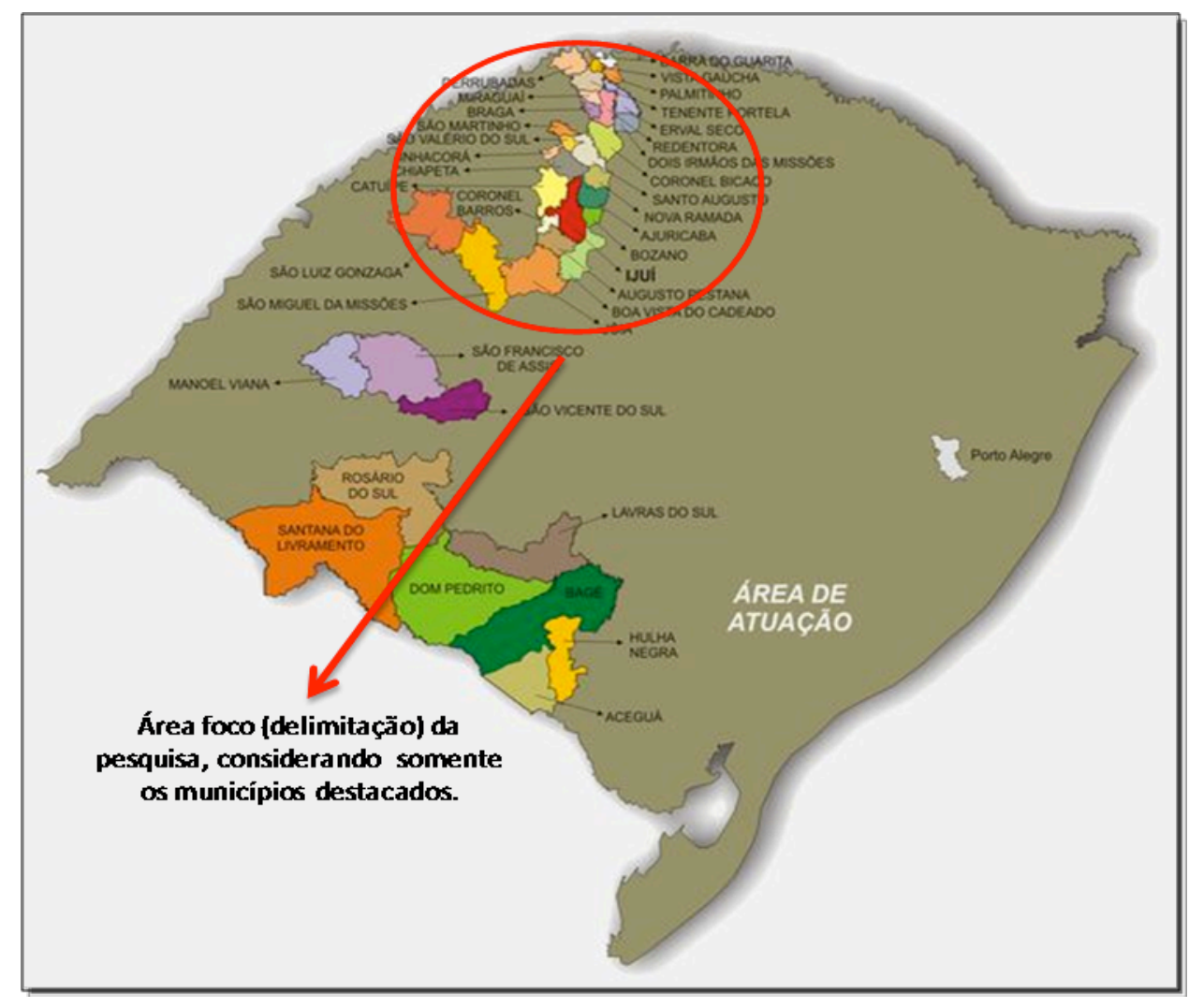

Figura 1- Delimitação/municípios inclusos na pesquisa.

Fonte: Adaptado de www.cotrijui.coop.br:8080/pg_empresa/areaatuacao.html

Para o processo de mobilização social, a CCGL Lácteos contou com a parceria das cooperativas associadas e tinha como objetivo: aumentar a produção leiteira, com acréscimo de lucratividade nas propriedades rurais e garantindo o desenvolvimento sustentável do setor primário. Porém, se entende como necessário, ao analisar essa experiência de mobilização social, identificar de que desenvolvimento ela trata ou que tipo de desenvolvimento ela busca, 
sendo este mais um dos objetivos do trabalho. Desta forma, cabe identificar se a CCGL visava o desenvolvimento para os atores sociais envolvidos ou o seu próprio desenvolvimento econômico? O que entende por desenvolvimento sustentável? Com base nessas questões, se buscou analisar criticamente essa estratégia de MS, considerando o alcance e os resultados da mesma, ou seja, se atingiu os objetivos iniciais. Para tanto, se utilizou literaturas que abordam o tema desenvolvimento e as estratégias para atingi-lo.

\section{Procedimentos Metodológicos}

Com base nas características e na natureza da investigação, esse estudo se enquadra numa pesquisa qualitativa e utiliza como método o Estudo de Caso. Como técnicas de pesquisa foram utilizadas a revisão de materiais bibliográficos ${ }^{2}$ e secundários (para compor o corpo teórico e empírico do trabalho) e a entrevista ${ }^{3}$ (para aprofundamento do caso "a campo").

As entrevistas ocorreram, como pode ser observado na Figura 2, com informantes chaves: produtores rurais e presidentes dos Sindicatos dos Trabalhadores Rurais (STRs) das cidades da área de abrangência da Cotrijuí. Para a realização desse trabalho e na busca de compor a base de dados empíricos para análise da MS coordenada pela CCGL, foram consultadas diferentes fontes de dados secundários, sendo eles: a) levantamento de informações em sites ${ }^{4}$; b) levantamento de informações em jornal (Jornal Folha); c) consulta a fonte de dados de rádio ${ }^{5}$ d) acompanhamento de palestras, seminários, debates.

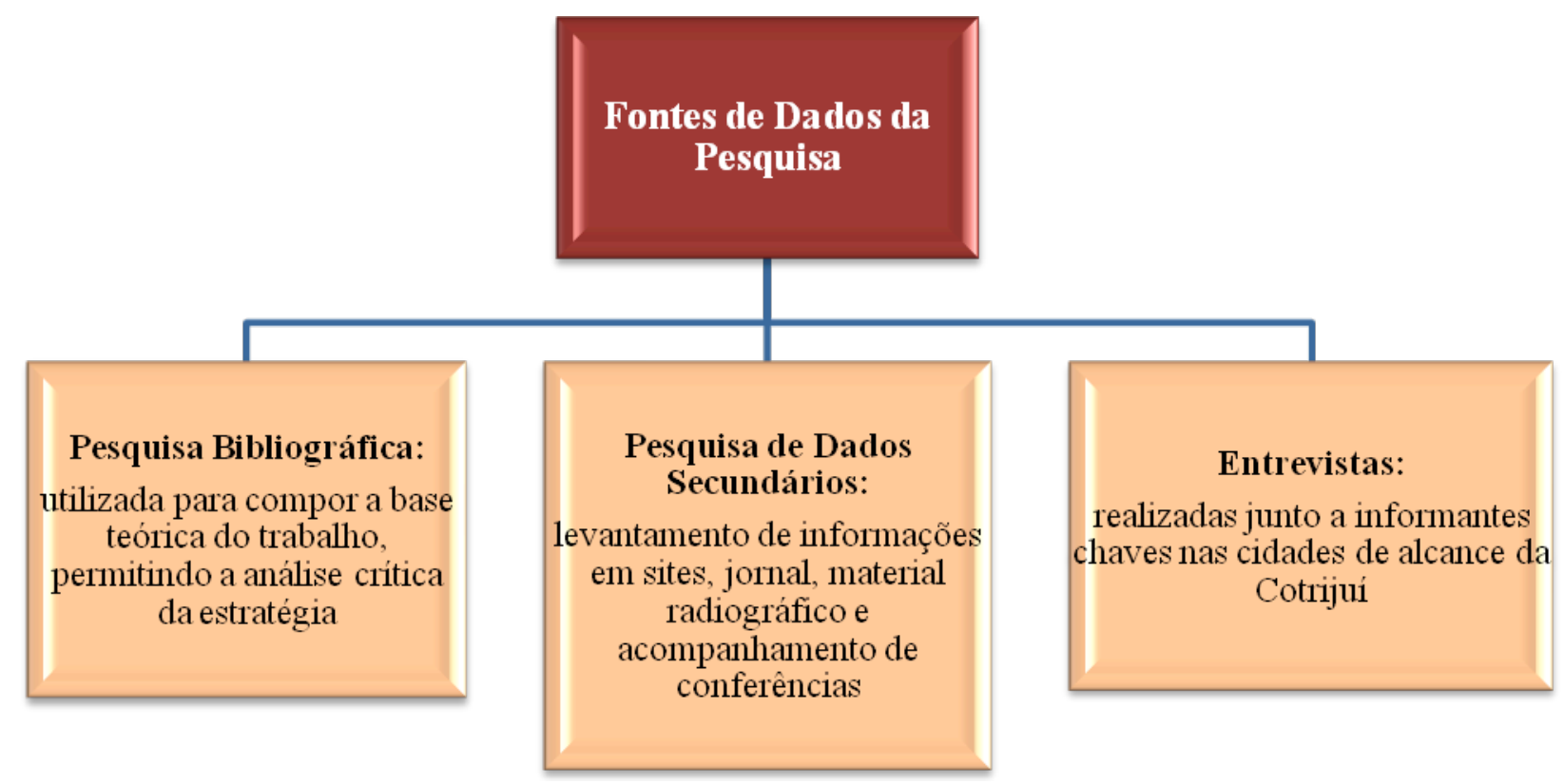

Figura 2- Fonte de dados para realização da pesquisa.

Fonte: Elaborada pelos autores

\footnotetext{
${ }^{2} \mathrm{O}$ cunho bibliográfico da pesquisa remete ao termo bibliografia que, de acordo com Santos (2007), diz respeito a um conjunto de materiais escritos (gráfica ou eletronicamente) a respeito de um assunto; sendo uma preciosa fonte de informações que contêm dados já organizados e analisados.

3 Técnica de Pesquisa definida como um encontro entre duas pessoas, a fim de que uma delas obtenha informações a respeito de determinado assunto, mediante uma conversação de natureza profissional. É considerado um importante instrumento de trabalho nos vários campos das ciências sociais, ou outros setores como pesquisas de mercado. (MARCONI e LAKATOS, 2003).

${ }^{4}$ www. cotrijui.coop.br; www.rpi.com.br; www.ccgl.com.br

${ }^{5}$ www.rpi.com.br
} 
Conceitualmente, o método da pesquisa é o que Yin (2005) define como sendo um estudo de caso, que é uma inquirição empírica que investiga um fenômeno contemporâneo dentro de um contexto da vida real, quando a fronteira entre o fenômeno e o contexto não é claramente evidente e onde múltiplas fontes de evidência são utilizadas. Deve-se usar o estudo de caso quando se quer lidar com condições contextuais - acreditando que elas podem ser altamente pertinentes ao fenômeno de estudo. Yin (2005) descreve que a forma de questão de pesquisa em estudo de caso se define em "como" e "porque" os fenômenos se apresentam. O estudo de caso não exige um controle sobre os eventos comportamentais e focaliza estudos contemporâneos.

Tal explanação atende às necessidades de saber como ocorre o processo de Mobilização Social coordenado pela CCGL na região noroeste do Estado do Rio Grande do Sul e porque os fatores vão se apresentar da forma como serão relatados, da mesma forma, o fato de não se fazer parte das relações que existem entre os agentes estudados, permite um afastamento do caso e a ausência de controle sobre os eventos. Esses eventos são contemporâneos e dinâmicos.

\section{Apresentação do Caso: estratégias de mobilização social da CCGL Lácteos na busca do aumento da produção leiteira na região de abrangência da Cotrijuí}

\subsection{Aspectos Gerais}

Para o entendimento do processo de mobilização social analisado, se faz necessário descrever o contexto em que está inserida a CCGL Lácteos e os produtores de leite da região analisada. Um dos aspectos mais significativos e intrigantes desta última década na cadeia produtiva leiteira é a mudança que se tem observado nas estruturas de alguns mercados da matéria prima (mercado entre indústria e produtor). Na década de 90 , o fim da intervenção do Governo no setor de laticínios e a abertura comercial, fez com que aumentasse a concorrência entre as empresas, provocando redução nos preços, estratégias de lançamento de novos produtos e aumento no volume de produção, além de crescimento da oferta de produtos lácteos. Esse cenário veio acompanhado de mudanças na estrutura produtiva, com predominância de multinacionais e faturamentos industriais elevados.

Frente a essa concorrência, as empresas de laticínios apresentaram diferentes estratégias comerciais junto ao produtor, pois elas buscaram aumentar o volume de captação com redução no número de produtores. Segundo Breitenbach (2008) na década de 90 a concorrência entre empresas processadoras para a compra de matéria-prima não se estabeleceu de forma significativa, sendo, na maioria dos casos, uma indústria apenas responsável pela captação de leite em uma determinada região. Porém, em especial a partir de 2004, tem-se observado mudanças neste cenário (principalmente na região noroeste do Rio Grande do Sul), com aumento no número de empresas processadoras e processos de concorrência em curso entre empresas laticinistas pela aquisição da matéria prima junto aos produtores (BREITENBACH, 2008).

$\mathrm{Na}$ região foco da pesquisa, de 2004 até 2008, várias novas empresas de grande e pequeno porte passam a captar o leite na região. O leite que até então era adquirido por apenas uma empresa processadora, passou a ser repartido com as outras, dando início a uma disputa. Esse aumento no número de compradores do leite pode ser atribuído à concentração de produtores de leite na região (uma pequena área geográfica) com produtividades 
significativas, o que reduz custos de transporte e gera ganhos de escala para as empresas processadoras.

Esse processo gerou um aumento significativo no preço pago ao produtor pelo leite e como as informações de mercado acerca desse processo (oligopsônio concorrencial ${ }^{6}$ ) eram limitadas aos agricultores - esse aumento, combinado ao processo de MS comandado pela CCGL, fez com que os agricultores passassem a fazer expressivos investimentos na atividade. Considera-se que a CCGL teve, a partir de um processo de mobilização social aqui analisado, grande contribuição para o aumento da produção. Porém, não foi possível quantificar a participação da cooperativa, mas buscou-se trazer dados qualitativos na tentativa de descrever o processo.

\subsection{Agentes Envolvidos}

Como pode ser observado na Figura 3, existem três atores considerados como fundamentais no processo analisado. Em primeiro lugar, se tem o agente que coordenou o processo de mobilização social para o aumento da produção de leite, que foi a CCGL; em segundo lugar, se destaca a Cotrijuí, a qual colaborou diretamente no processo, especialmente pelo contato mais próximo e recorrente com os agricultores; por fim, os públicos alvos da ação, que são os agricultores produtores e fornecedores de leite in natura. A seguir são descritas as principais características de cada um dos atores envolvidos e aqui considerados como fundamentais.

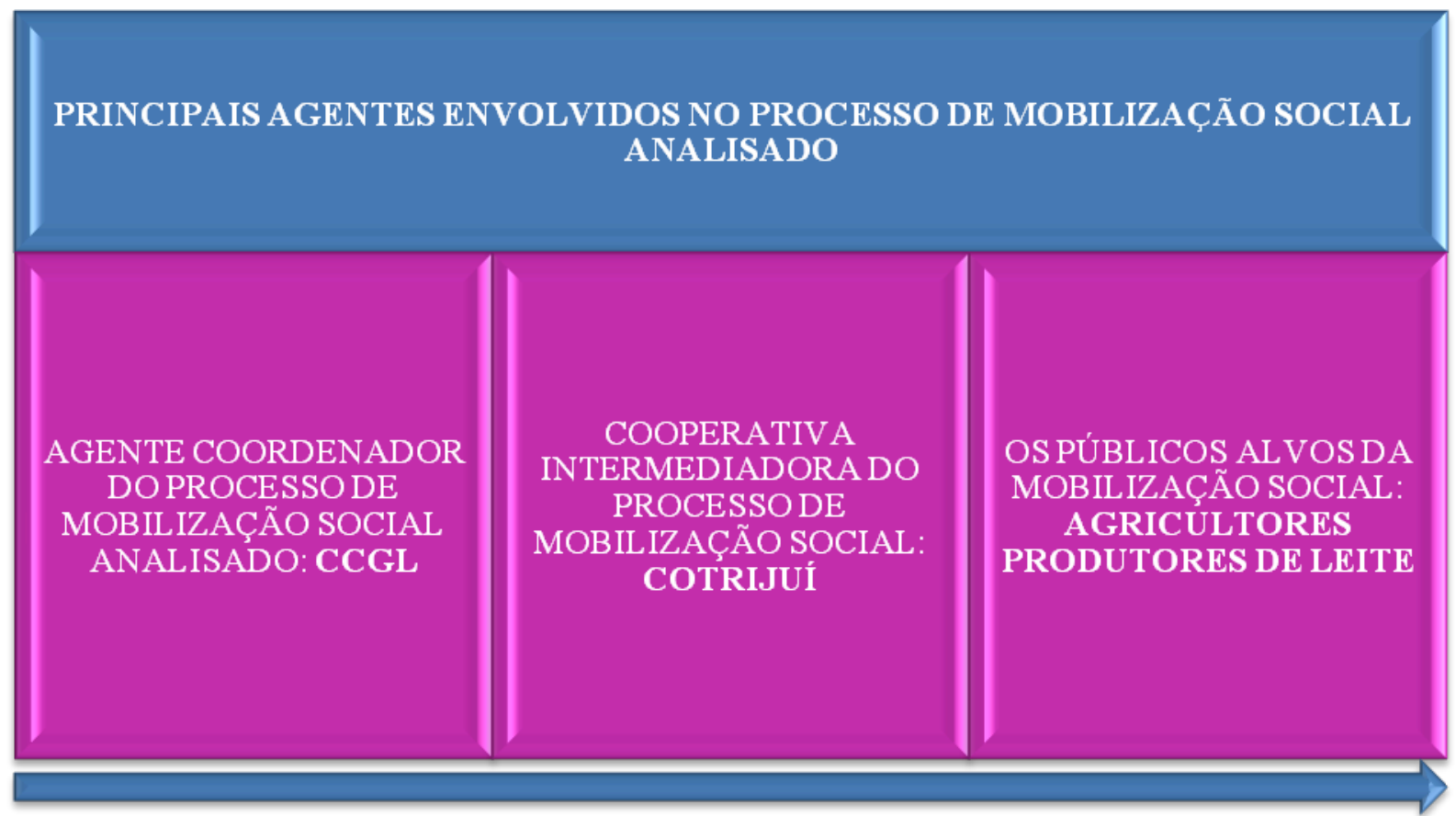

Figura 3- Agentes envolvidos no processo de mobilização social analisado Fonte: Elaborada pelos autores

\footnotetext{
${ }^{6}$ Um oligopsônio é uma estrutura de mercado caracterizada por um número restrito de agentes efetuando compras de determinado produto - geralmente ofertado por um número considerável de agentes. No caso do oligopsônio concorrencial, os poucos agentes demandantes concorrem entre si e não usam de medidas que são comuns para a distorção da estrutura de mercado. São essas medidas: formatação de acordos, formação de cartéis, conluios, etc.
} 
a) CCGL-Cooperativa Central Gaúcha de Leite. A CCGL foi fundada no Rio Grande do Sul em 21 de Janeiro de 1976, para a organização econômica de pequenos produtores (com menos de $50 \mathrm{ha}$ ) na busca de alternativas à monocultura da soja e do trigo. Inicialmente integrava 35 cooperativas filiadas e foi resultado do Projeto Integrado de Desenvolvimento do Cooperativismo (PIDCOOP) do governo federal.

b)

A primeira unidade industrial foi inaugurada no ano de 1978 no município de Ijuí. No início da década de 90 a CCGL foi transformada em sociedade anônima e mantinha contato com 27 cooperativas secundárias. Em 1995 o parque industrial da CCGL foi comprado pela Avipal, passando a receber o nome de Elegê Alimentos. Essa venda se deveu ao alto endividamento das várias cooperativas de soja associadas à CCGL, e se formatou sem maiores consultas a seus associados de base.

Já na primeira fase, a CCGL desenvolveu um trabalho importante para a expansão da produção leiteira, transformando a Mesorregião Noroeste na maior bacia leiteira do estado. A CCGL continuou existindo, mas trabalhando apenas com o escoamento da produção de Soja no RS. No ano de 2005 a Central anunciou que retornaria suas atividades no setor de laticínios no município de Cruz Alta (RS); sendo esta unidade inaugurada em 9 de Outubro de 2008, com início da coleta de leite no dia 01 de Novembro deste mesmo ano.

b) Cooperativa Intermediadora do Processo - Cotrijuí. A cooperativa responsável pela região foco deste estudo e que intermedia as transações entre agricultor/CCGL é a Cotrijuí. Foi fundada aos 20 dias de julho de 1957 e tinha o objetivo inicial de:

Congregar os plantadores de trigo da região, para promover a defesa de seus interesses econômicos [...], e superar as dificuldades de comercialização da safra de trigo que vem se avolumando de ano para ano (COTRIJUÍ, 2008).

As estratégias de mobilização social, para atingir os objetivos da CCGL, são elaboradas e realizadas em conjunto com a Cotrijuí. Portanto, destaca-se a importância desse agente para o processo analisado, o que o torna um dos atuantes focos da pesquisa.

c) O Público-Alvo da Mobilização Social-Agricultores Produtores de Leite. A região foco desse estudo é a região noroeste do estado do Rio Grande do Sul que possui a economia com base na agropecuária e tem como principais produtos o soja, trigo, milho e leite. Os agricultores produtores de leite da região são quase na totalidade (em torno de 97\%) agricultores familiares.

O termo agricultura familiar é aqui utilizado com base em Schneider (2006) que disserta que a permanência da agricultura familiar no tempo não é estática e dependerá da sua relação com formas distintas e heterogêneas de estruturação social, cultural e econômica do capitalismo, em certo espaço e contexto histórico. Por isso, alerta para a necessidade de abandono do raciocínio dualista, tipológico e ordenador da heterogeneidade social e econômica que caracteriza as formas familiares de produção.

Como contribuição teórica, o autor elabora elementos úteis para uma definição mais abrangente da agricultura familiar - sendo essas perfeitamente aceitáveis às características 
encontradas na região do estudo: forma de uso do trabalho (força de trabalho dos membros da família); obstáculos oferecidos pela natureza que impedem uma eventual correspondência entre a atividade produtiva agrícola e industrial (tempo de trabalho menor que tempo de produção); compreensão das formas de articulação da agricultura familiar com o ambiente social e econômico em que estiver inserida. Como uma característica importante, o autor cita a natureza familiar das atividades agrícolas, que estão assentadas nas relações de parentesco e de herança existentes entre seus membros. Isso permite agilidade nas decisões e nas ações. Portanto, "a reprodução é, acima de tudo, o resultado do processo de intermediação entre os indivíduos-membros com sua família e de ambos interagindo com o ambiente social em que estão imersos" (SCHNEIDER, 2006, p. 26).

Os agricultores da região de estudo possuem a bovinocultura de leite como uma atividade tradicional e muito importante social e economicamente. Social pela alta exigência de mão-de-obra, que faz com que diminua a migração rural-urbana. Econômica por permitir uma renda mensal e diversificada, com a qual a família se mantém (alimentação, saúde, educação, etc.), enquanto as demais atividades, basicamente soja, milho e trigo, permitem uma renda para investimentos e para cobrir demais despesas.

Historicamente a bovinocultura de leite é uma atividade com constantes oscilações, hora com condições favoráveis e se tornando lucrativa, hora com significativos prejuízos para os agricultores. O movimento sindical regional, ligado a FETAG-RS (Federação dos Trabalhadores na Agricultura do Rio Grande do Sul), desenvolveu ao longo da sua história muitos debates e mobilizações na busca da rentabilidade da atividade, especialmente a partir da redução das margens de lucro das empresas processadoras, consideradas exorbitantes.

\subsection{Estratégias de Mobilização Social Utilizadas pela CCGL}

Para a efetivação dos projetos de mobilização social se torna fundamental o estabelecimento de processos comunicativos com os sujeitos, na busca de despertar interesse e obter legitimidade pública. Para isso, considera-se a importância dos meios, instrumentos e técnicas de comunicação, bem como da mídia de massa. Os apelos emotivos, ao serem combinados com ações espetaculares e festivas, bem como com argumentos racionais, tornam mais fácil o ingresso dos temas na esfera pública (MAFRA, 2006). Já Bohman (2000, p.32) afirma que:

[...] as ações na esfera pública não podem ser meramente tarefas estratégicas, porque, por mais que essas estratégias sejam importantes, principalmente no sentido de promover visibilidade para diversas causas, projetos e movimentos devem formular razões para que suas necessidades e problemas mereçam atenção coletiva diante da esfera pública.

Essa etapa do trabalho buscou caracterizar as estratégias utilizadas pela CCGL, com base na classificação de Baitello Junior (2001) em mídia primária, secundária e terciária e, também, baseado em Mafra (2006), classificar os espaços de visibilidade pública a que se direcionou as estratégias em: midiático massivo, midiático massivo local, dirigido, o presencial e o telemático. Com base nesse mesmo autor, buscou-se ainda classificar a dimensão das estratégias em: espetacular, festiva e argumentativa.

Para compreensão das análises, se destaca que o papel da mídia é considerado fundamental, se tratando de uma "instância privilegiada para gerar visibilidade e, com uma força simbólica considerável, conferir existência pública a temas que antes poderiam não ser 
problematizados com tamanho alcance e audiência" (MAFRA, 2006, p. 40). Além disso, a mídia é mais que uma difusora de informações, tem autonomia relativa e pode privilegiar questões a partir de mecanismos próprios. Com isso, não proporciona uma competição justa entre os grupos e/ou chances iguais para se manifestar.

Pross (1971) classifica o sistema de mediação em: a) Mídia Primária - o indivíduo utiliza o corpo para se comunicar, e, por ser realizada pelo contato interpessoal, não necessita de mediação. Entram em jogo, neste caso, as expressões (olhos, testa, boca, movimentos, rituais, linguagens, etc.); b) Mídia Secundária - composta pelos meios de comunicação que levam a mensagem ao receptor sem que este precise de aparelhos para captar o significado da mensagem (imagem, escrita, o impresso, gravuras, fotografias, máscaras, pinturas, adereços corporais, etc.); c) Mídia Terciária- nesse caso, tanto o emissor quanto o receptor precisam de aparato para se comunicar ( $\mathrm{TV}$, rádio, internet, telegrafia, telefonia, cinema, discos, fitas, CD's, etc.).

Para Mafra (2006) um espaço de visibilidade pública é considerado um espaço físico ou mediado, no qual um tema torna-se visível e disponível para uma determinada coletividade. Com essa definição, o autor afirma que ações estratégicas planejadas por projetos de mobilização social podem estar direcionadas a cinco possíveis espaços de visibilidade pública:

a) Espaço de visibilidade midiático massivo - gerado por meios de comunicação (TV, rádio, jornal, revista) e com alcance para um grande número de pessoas e num território geográfico amplo. Para tanto, as informações que circulam não têm especificidades de linguagem ou tratamento de informação direcionado ao público alvo;

b) Espaço de visibilidade midiático massivo local - difere-se do anterior pela área de abrangência, ou seja, direciona-se a um território geográfico menor;

c) Espaço de visibilidade dirigido - realizado por veículos de comunicação (programas de TV e rádio, jornais, revistas, encontros, seminários, etc.) direcionados para públicos específicos. Por isso, adequam as informações que serão visíveis a partir do quadro de entendimentos, valores, expectativas de tais públicos; indivíduos;

d) Espaço de visibilidade presencial - compartilhado presencialmente pelos

e) Espaço de visibilidade telemático - gerado na Rede Mundial de Computadores (Internet), com alcance limitado, construído principalmente por meio de sites, fóruns, portais, blogs, etc.

Acerca das dimensões das estratégias comunicativas, Mafra (2006) classifica-as em: a) dimensão espetacular - objetiva chamar a atenção, despertar o interesse, capturar a atenção dos sujeitos, promover existência pública às causas sociais; b) dimensão festiva - permite o engajamento in loco dos indivíduos, ocasiona a vivencia e o lúdico, podem ser manifestações de rua, festas populares, eventos e demais momentos de encontro planejados por projetos de mobilização social; c) dimensão argumentativa - torna disponível publicamente argumentos que justifiquem uma transformação coletiva ampla, explica as razões da existência pública da causa e, além de estimular a incorporação de demandas propostas, estimula e sustenta um debate público.

Conforme pesquisa de campo; levantamento de informações em sites, jornais, fonte de dados de rádio; acompanhamento de palestras, seminários, debates, junto a produtores rurais e 
a Cotrijuí; bem como observação de conversas informais entre produtores e funcionários (técnicos) da Cotrijuí, pôde-se identificar, analisar e classificar as seguintes estratégias de mobilização social conforme apresentado no Quadro 1.

Foi analisado cada um dos eventos e/ou notícias que se teve acesso a partir da pesquisa realizada. Os resultados buscam destacar: 1) a data da notícia ou evento, a forma de veiculação (no caso de ser notícia); 2) o tema ou manchete da notícia ou evento; 3) é destacado se o evento ou notícia está diretamente relacionado a ação da CCGL; 4) classificouse os meios de comunicação utilizados para cada evento ou notícia em primário, secundário ou terciário, sendo que cada evento ou notícia poderiam utilizar os três meios ou não; 5) classificou-se as ações quanto ao espaço de visibilidade público em: a- espaço de visibilidade midiático massivo; b- espaço de visibilidade midiático massivo local; c- espaço de visibilidade dirigido; d- espaço de visibilidade presencial; e- espaço de visibilidade telemático; 6) por fim, foram classificadas as ações (notícias ou evento) quanto as suas dimensões estratégicas em: a- dimensão espetacular; b- dimensão festiva; c- dimensão argumentativa.

Pode-se dizer que a CCGL utilizou-se do que Mafra (2006, p.42) chama de comunicação estratégica que, segundo ele:

[...] representa uma forma de construir e estabelecer processos comunicativos de forma planejada, e não espontânea. De maneira geral, a necessidade de pensar a comunicação de forma estratégica veio em decorrência da emergência de uma sociedade moderna, com a consolidação dos regimes políticos democráticos, com a formação de uma determinada opinião pública e com a preocupação, imposta a inúmeras instituições, de estabelecer uma atividade que cuidasse especificamente da relação dessas instituições com públicos a ela vinculados direta ou indiretamente. 


\begin{tabular}{|c|c|c|c|c|c|c|c|c|c|c|c|c|c|c|c|c|c|}
\hline $\begin{array}{l}u \\
\dot{0} \\
\tilde{\tilde{O}} \\
\dot{\infty}\end{array}$ & 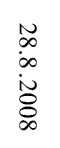 & $\begin{array}{l}\frac{N}{\infty} \\
\infty \\
\tilde{N} \\
\infty \\
\infty\end{array}$ & $\left|\begin{array}{l}\vec{u} \\
\infty \\
\dot{\tilde{a}} \\
\dot{\infty} \\
0\end{array}\right|$ & $\begin{array}{l}0 \\
\infty \\
\infty \\
\dot{1} \\
\stackrel{0}{\infty}\end{array}$ & $\begin{array}{l}\stackrel{0}{\sim} \\
\stackrel{\sim}{\tilde{O}} \\
\stackrel{0}{\infty}\end{array}$ & $\begin{array}{l}\text { w. } \\
\dot{\alpha} \\
\dot{\tilde{O}} \\
\dot{\infty}\end{array}$ & $\begin{array}{l}\vec{F} \\
\dot{\hat{u}} \\
\dot{o}\end{array}$ & $\begin{array}{l}\omega \\
\dot{\hat{\alpha}} \\
\dot{\tilde{O}}\end{array}$ & $\begin{array}{l}\overrightarrow{\bar{u}} \\
\ddot{\tilde{u}} \\
\dot{\infty}\end{array}$ & 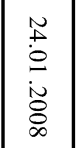 & 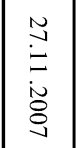 & $\begin{array}{l}\infty \\
\dot{0} \\
\dot{\tilde{u}} \\
\stackrel{0}{u}\end{array}$ & $\begin{array}{l}\bar{Z} \\
\dot{\alpha} \\
\dot{\tilde{o}} \\
\dot{g}\end{array}$ & $\begin{array}{l}\tilde{u} \\
\ddot{u} \\
\ddot{\tilde{o}} \\
\tilde{o}\end{array}$ & $\begin{array}{l}\stackrel{+}{ \pm} \\
\dot{\tilde{n}} \\
\stackrel{o}{u}\end{array}$ & 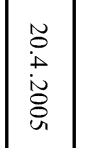 & $\stackrel{\Xi}{\ddot{Z}}$ \\
\hline 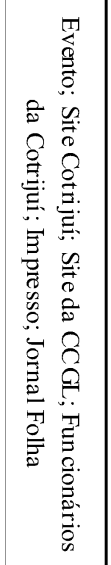 & 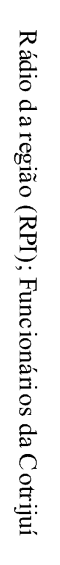 & 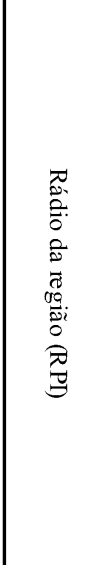 & 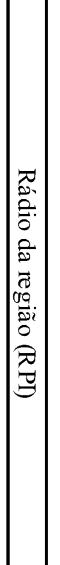 & 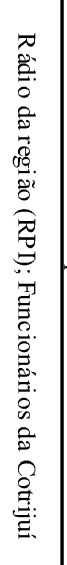 & 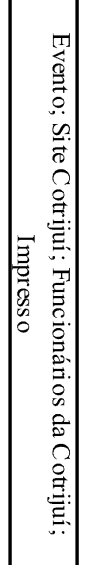 & 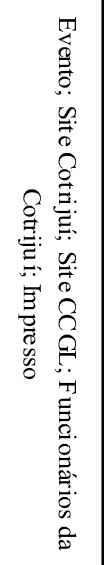 & 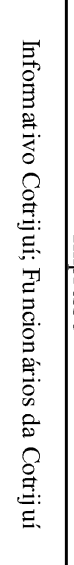 & \begin{tabular}{|l|} 
\\
\\
\end{tabular} & 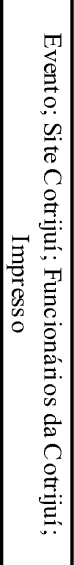 & 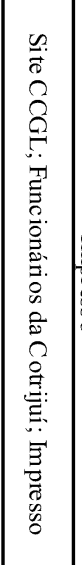 & 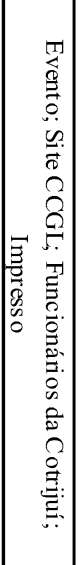 & 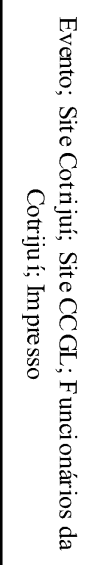 & 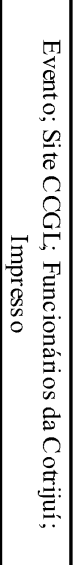 & 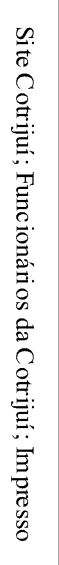 & 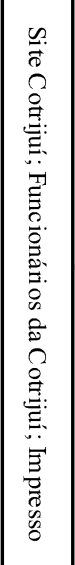 & 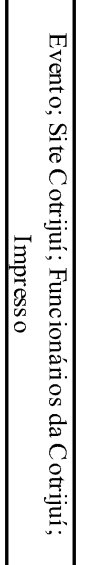 & 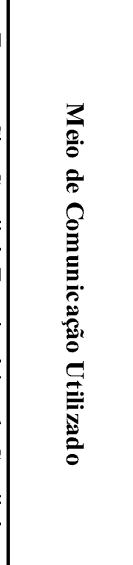 \\
\hline 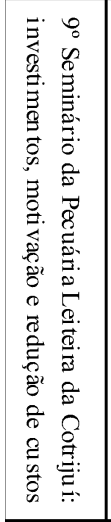 & 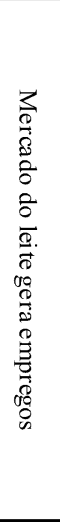 & 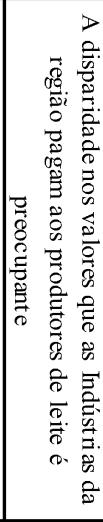 & & 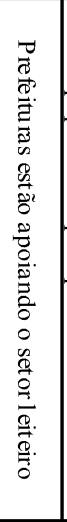 & 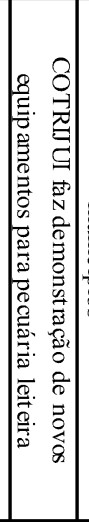 & 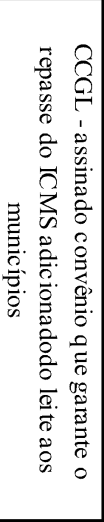 & 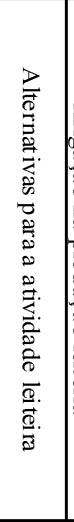 & 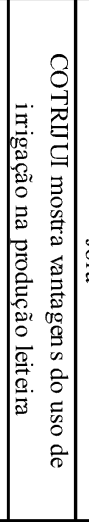 & 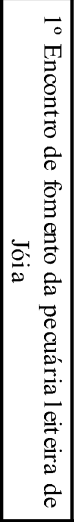 & 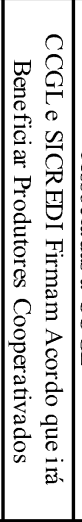 & 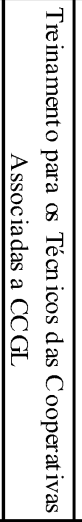 & 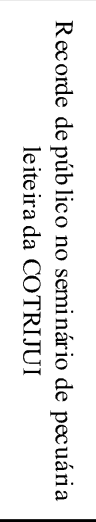 & 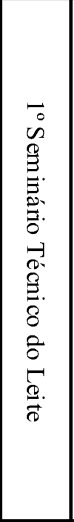 & 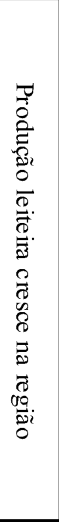 & 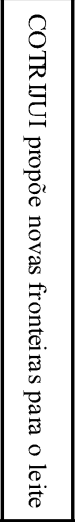 & 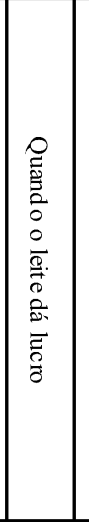 & 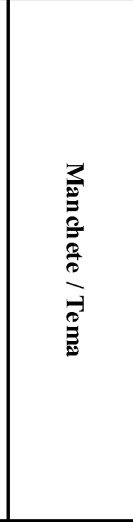 \\
\hline$\Xi$ & $\underline{E}$ & 疍 & $\mid \begin{array}{c}z \\
z^{2} \\
0^{2}\end{array}$ & $\underset{\underset{o}{\prime \prime}}{Z}$ & $\underline{\Xi}$ & $\tilde{g}^{0}$ & $\underline{\Xi}$ & $\tilde{\Xi}^{2}$ & $\stackrel{0}{E}$ & 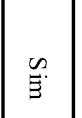 & $\tilde{E}^{n}$ & $\underline{\underline{E}}$ & E. & $\tilde{s}^{2}$ & $\stackrel{n}{\tilde{E}}$ & $\Xi$ & 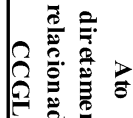 \\
\hline 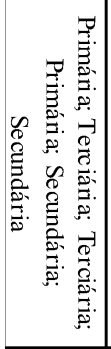 & 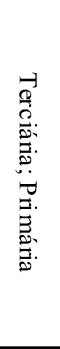 & 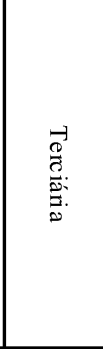 & 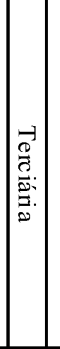 & 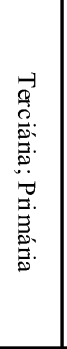 & 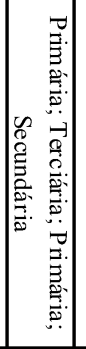 & 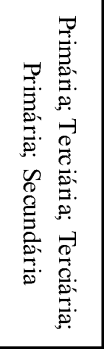 & 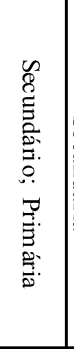 & 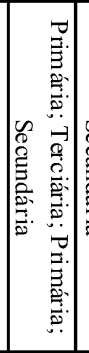 & 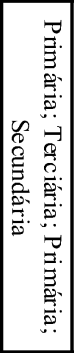 & 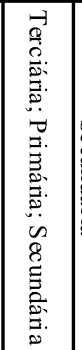 & 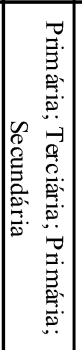 & 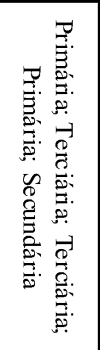 & 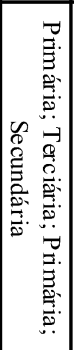 & 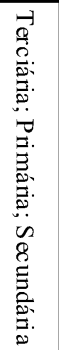 & 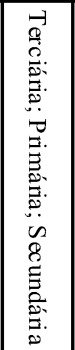 & 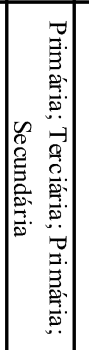 & 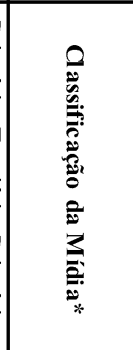 \\
\hline 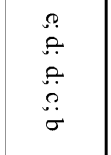 & 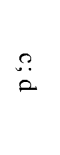 & 0 & 10 & $\stackrel{\leftrightarrow}{\ddot{n}}$ & 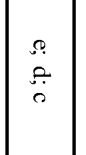 & 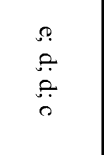 & $\ddot{a}$ & 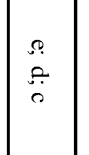 & 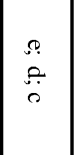 & 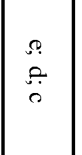 & 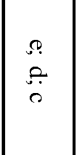 & 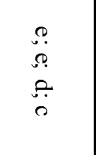 & 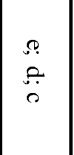 & 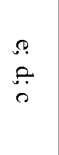 & $\begin{array}{l}\stackrel{0}{0} \\
\stackrel{0}{0}\end{array}$ & 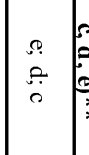 & 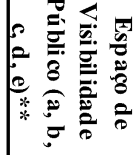 \\
\hline יָ & סִ & $z_{0}$ & 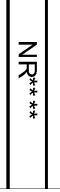 & 0 & 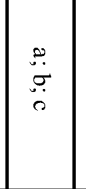 & $\ddot{\circ}$ & 0 & 0 & 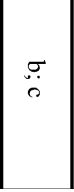 & 范 & 0 & $\ddot{\circ}$ & 0 & 0 & 0 & 1 & 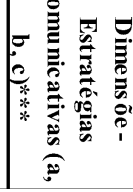 \\
\hline
\end{tabular}




\begin{tabular}{|c|c|c|c|c|c|c|c|c|c|c|c|c|c|c|}
\hline 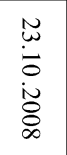 & 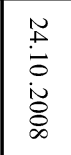 & 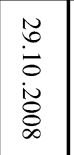 & 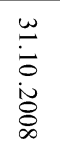 & 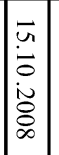 & $\begin{array}{l}\vec{u} \\
\overrightarrow{0} \\
\tilde{\tilde{O}} \\
\dot{\infty}\end{array}$ & 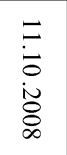 & $\begin{array}{l}\stackrel{8}{0} \\
\dot{0} \\
\dot{\tilde{O}} \\
\dot{0}\end{array}$ & $\begin{array}{l}\bar{\omega} \\
\dot{\overrightarrow{0}} \\
\dot{\tilde{O}} \\
\dot{\infty}\end{array}$ & $\begin{array}{l}\mathscr{U}_{0} \\
\dot{\tilde{u}} \\
\dot{\tilde{O}} \\
\dot{\infty}\end{array}$ & 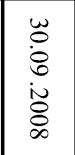 & 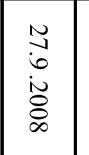 & $\begin{array}{l}\vec{\infty} \\
\dot{0} \\
\dot{\tilde{O}} \\
\dot{\infty}\end{array}$ & 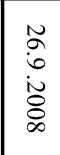 & 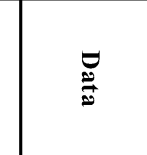 \\
\hline 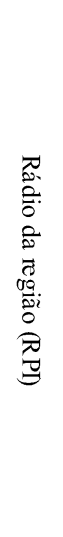 & 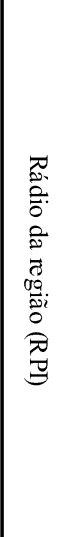 & 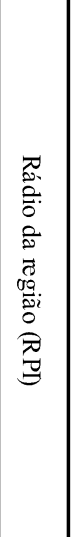 & 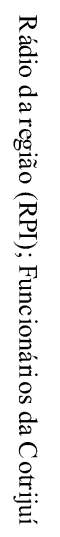 & 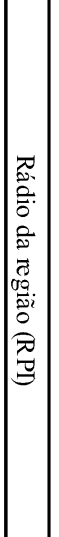 & 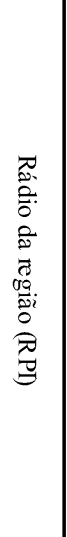 & 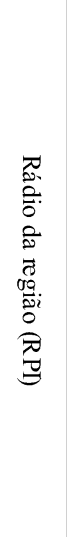 & 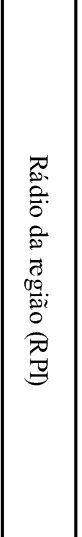 & 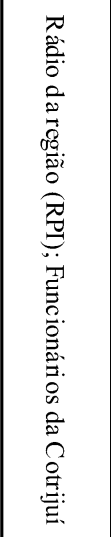 & 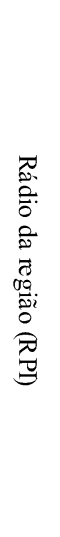 & 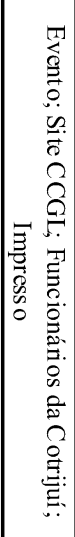 & 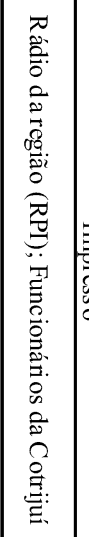 & 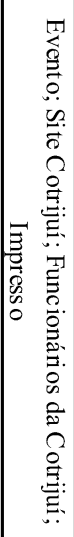 & 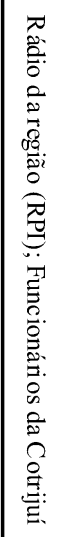 & 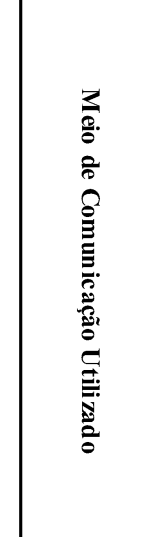 \\
\hline 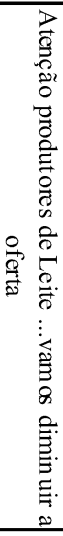 & 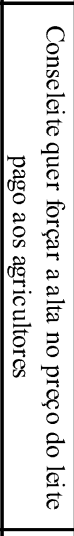 & 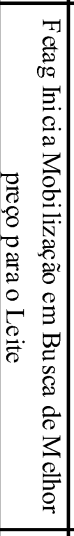 & 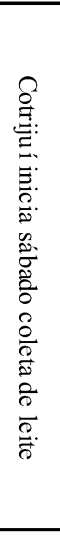 & 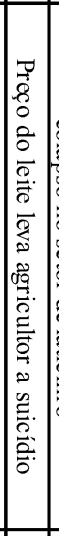 & 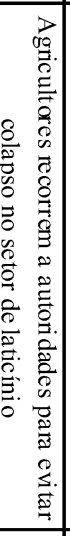 & 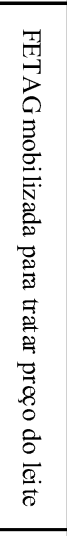 & 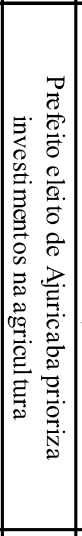 & 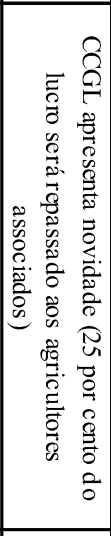 & 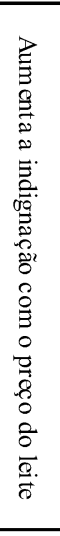 & 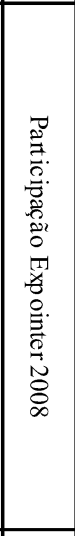 & 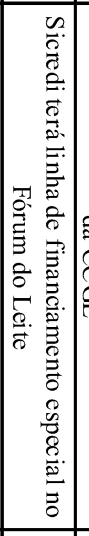 & 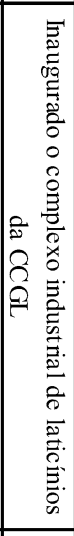 & 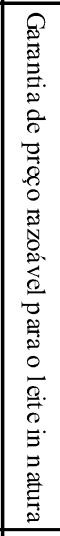 & 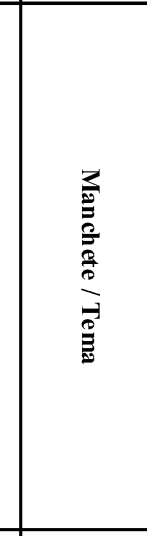 \\
\hline$\underset{\tilde{\sigma}}{Z}$ & $\underset{\tilde{z}}{Z}$ & $\underset{\tilde{\partial}}{Z}$ & E. & $\mid$\begin{tabular}{|l|}
$z$ \\
$\vec{o}^{\prime}$
\end{tabular} & $\begin{array}{l}Z \\
\vec{z}\end{array}$ & 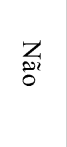 & $\underset{\ddot{O}}{Z}$ & $\underline{n}$ & $\underset{\tilde{O}^{2}}{Z}$ & : & $\stackrel{0}{0}$ & 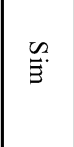 & $\underline{\Xi}$ & 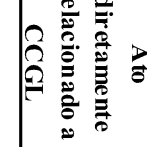 \\
\hline : & 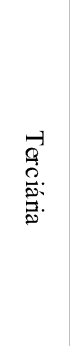 & 常: & 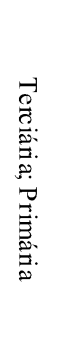 & 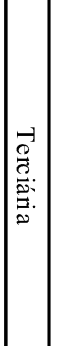 & : & 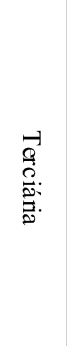 & 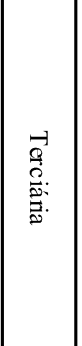 & 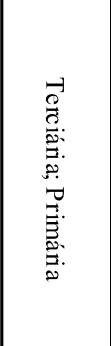 & 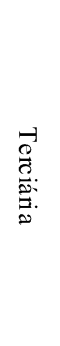 & 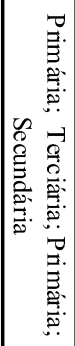 & 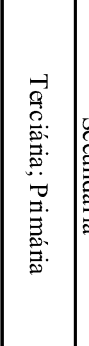 & 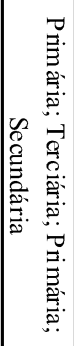 & 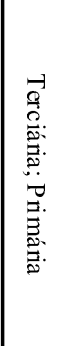 & 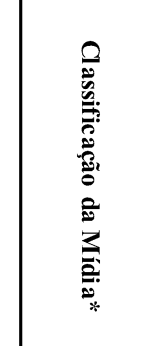 \\
\hline 0 & 0 & 0 & $\stackrel{\mathscr{Q}}{\mathscr{2}}$ & 0 & 。 & 0 & 0 & $\stackrel{?}{\ddot{Q}}$ & 0 & 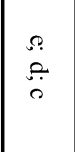 & $\stackrel{?}{a}$ & 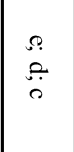 & $\stackrel{?}{:}$ & 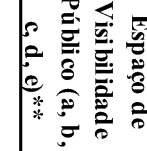 \\
\hline Z & Z & Z & $\sigma$ & $z_{0}$ & Z & Z & 0 & 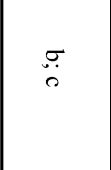 & Z & 它 & 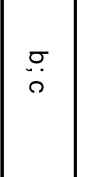 & مَّ & 0 & 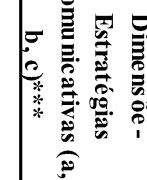 \\
\hline
\end{tabular}

Fonte: Elaborada e organizada pela autora

* Nível de análise relacionado aos meios de comunicação (ou estratégia no caso de ter

"Evento") na ordem que foram listados na coluna "Meios de Comunicação Utilizados". 
** A ordem de análise corresponde a ordem dos meios de comunicação listados na coluna "Meios de Comunicação Utilizados" (a- espaço de visibilidade midiático massivo; b- espaço de visibilidade midiático massivo local; c- espaço de visibilidade dirigido; d- espaço de visibilidade presencial; e- espaço de visibilidade telemático);

*** A ordem de análise corresponde a ordem dos meios de comunicação listados na coluna

"Meios de Comunicação Utilizados" (a- dimensão espetacular; b- dimensão festiva; cdimensão argumentativa);

**** Fato/Evento Não Relacionado diretamente a CCGL.

A partir da análise do quadro, constata-se que foram muitas as estratégias de mobilização social utilizadas pela CCGL na busca de alcançar seu objetivo. Tal objetivo diz respeito a aumentar a produção de leite de forma lucrativa e promovendo o desenvolvimento rural.

Observa-se que o tipo de mídia que predominou nas estratégias foi a mídia terciária, sendo o rádio (emissora RPI - Rádio Progresso de Ijuí, AM, freqüência 104,5, site: www.rpi.com.br) o meio de maior alcance, visto que a internet ainda é um meio de comunicação de acesso limitado para a maioria dos agricultores. A mídia secundária acaba por dar um suporte às informações disponíveis na internet, já que as notícias lá postadas são impressas e entregues aos agricultores nas agências da Cotrijuí. Entende-se que a mídia terciária e a mídia secundária foram utilizadas como de apoio a mídia primária, visto que esta é a estratégia principal de mobilização social por parte da CCGL. Observa-se isso pelos vários eventos organizados pela CCGL em cooperação com a Cotrijuí, principalmente na forma de palestras, bem como o trabalho interpessoal face-a-face, realizado pelos técnicos da cooperativa diretamente com os produtores rurais.

Acerca das dimensões das estratégias comunicativas, constata-se que são, em sua maioria, de cunho argumentativo e, em raras exceções, festiva e espetacular. No que se refere ao espaço de visibilidade pública, nota-se que o espaço de visibilidade dirigido é o mais utilizado, seguido do espaço de visibilidade presencial e do espaço de visibilidade telemático. Em menor grau (aparecendo em um único evento) o espaço de visibilidade massivo local.

\subsection{Resultados do Processo de Mobilização Social}

O caso analisado demonstra que a CCGL Lácteos utilizou-se de várias estratégias comunicativas na busca da difusão de informações para o aumento da produção leiteira na região. Esse cenário, conseqüentemente, aumentaria a oferta de matéria-prima para sua indústria de laticínios.

Chama-se de difusão o processo pelo qual uma informação verdadeira ou falsa (um boato, por exemplo), uma opinião, uma atitude ou uma prática (por exemplo, a utilização de uma nova técnica agrícola ou de uma prática anticoncepcional) se expandem numa população dada (BOUDON, 1992, p. 161).

Constatou-se que o objetivo que diz respeito ao aumento da produção foi atingido, visto o significativo acréscimo na produção leiteira da região - Zanela et. al. (2006) já demonstravam que a região noroeste do RS concentrava $54,2 \%$ do leite produzido no Estado e, ainda constataram que a atividade estava em expansão na região e no Estado. No que se refere ao objetivo de garantia de lucratividade ao agricultor, nota-se que foi atingido num primeiro momento, porém, mudanças no mercado, combinadas com acordos entre empresas 
(possíveis cartéis), geraram uma redução brusca no preço do leite pago ao produtor, ocasionando problemas econômicos sérios a estes. Em série histórica de preços, de acordo com o trabalho de Viana et. al. (2010), se pode ter uma idéia desse comportamento dos preços (ver gráfico 1)

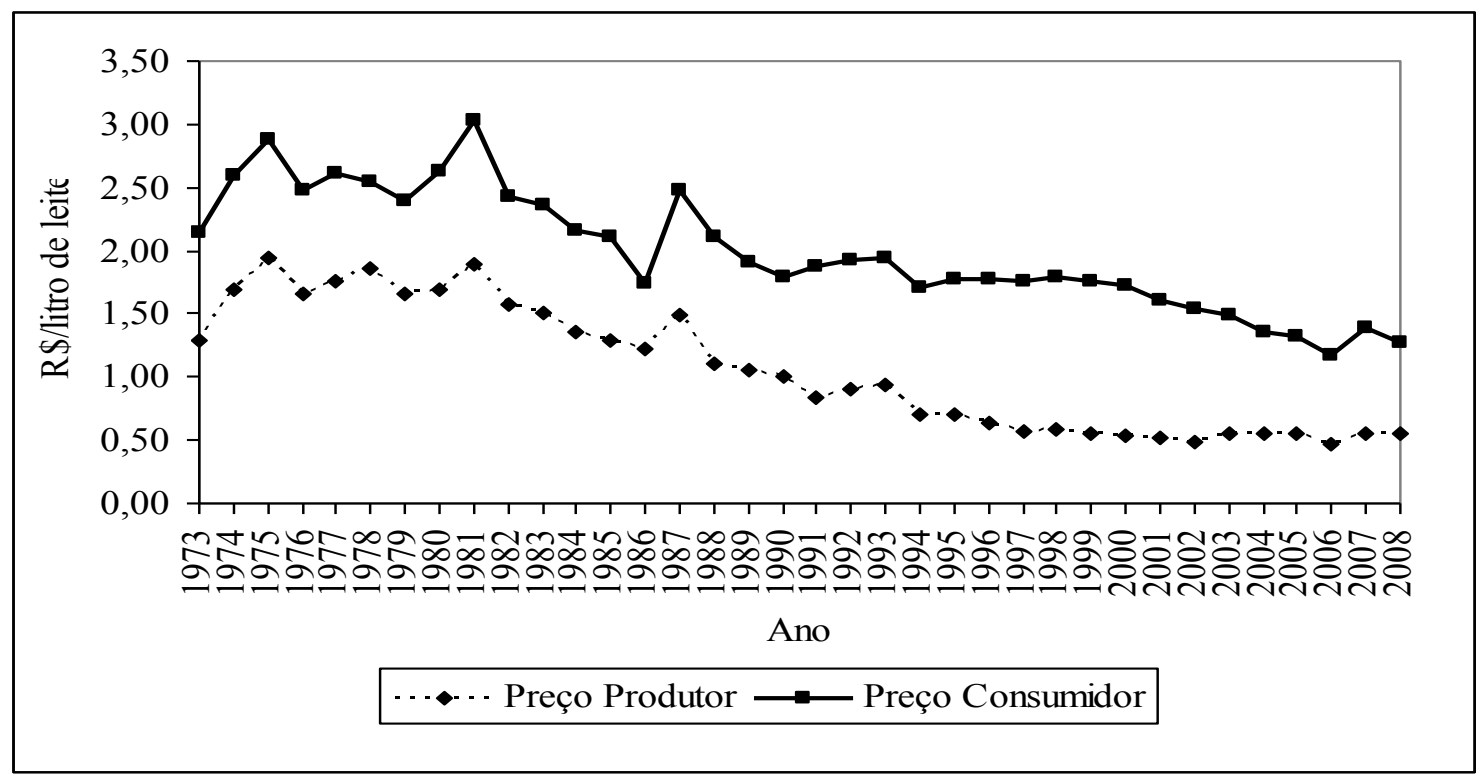

Gráfico 1 - Preços reais do leite ao produtor e ao consumidor no Rio Grande do Sul de 1973 a 2008. Fonte: Viana et. al. (2010).

Os investimentos realizados pelos agricultores têm retornos a longo prazo e foram financiados pelos bancos (Banrisul, Banco do Brasil, Sicredi). Porém, no final do segundo trimestre de 2008, além de um acréscimo significativo no preço dos insumos (rações, concentrados, adubos, etc.), também ocorreu uma forte redução no preço pago ao produtor pelo leite, dando sinais de que os investimentos foram feitos de forma exagerada, o que gerou preocupação para os produtores rurais, suas entidades representativas e para o poder público. A dificuldade para o pagamento das parcelas das dívidas começou a aparecer e a "boa recepção" antes tida nos bancos já não foi mais a mesma, pois há indícios claros de que muitos agricultores terão sérias dificuldades para cumprir os compromissos financeiros assumidos.

A CCGL juntamente com a Cotrijuí, (por serem cooperativas e pelos princípios cooperativos deveriam trabalhar em prol do benefício do agricultor) deveriam ter ressaltado aos agricultores os riscos da atividade e a necessidade de cautela nos investimentos. Constatase isso devido aos altos investimentos feitos pela maioria dos agricultores, investimentos estes de retorno a longo prazo e que, devido ao baixo preço do leite, terão dificuldades de pagar.

Duas notícias representam bem os problemas e contradições geradas pelo processo analisado (ver também Figura 3):

1 - 05 de Setembro de 2008, 15h44- $9^{\circ}$ Seminário da pecuária leiteira da Cotrijuí - Palavras do Presidente da CCGL, Caio Cezar Fernandes:

Fechamos dois anos de obra. Temos certeza que as cooperativas - a COTRIJUI e as demais 39 filiadas à CCGL, terão uma melhor condição para enfrentar o mercado. $\mathrm{O}$ aumento da produção não mais significará queda de preços. Isso é fruto da Força da União [...] A indústria é de vocês. (retirado do site www.cotrijui.coop.br). 
2 - 15 de Outubro de 2008, 15h56 - Preço do leite leva agricultor a suicídio - Agricultor com problemas de depressão, abalado com preço do leite comete suicídio por enforcamento no Interior de Augusto Pestana. Enquanto isso, FETAG está tomando as devidas ações para defender os interesses dos pequenos produtores (Notícia veiculada na Rádio Progresso de Ijuí).

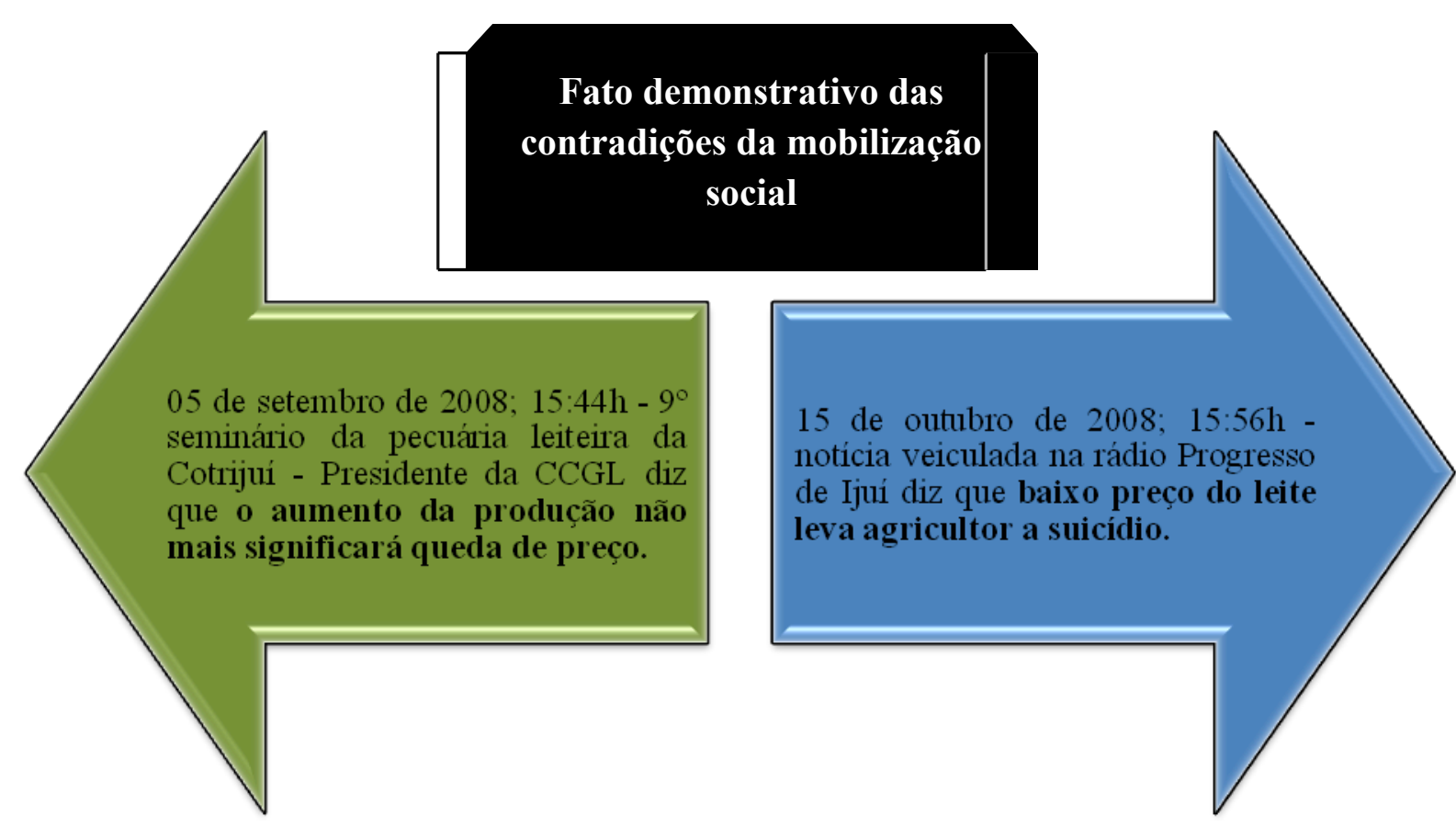

Figura 4 - Contradições evidentes da mobilização social analisada. Fonte: Elaborada pelos autores.

Com essas notícias, afloram as contradições e fica explícito um objetivo não cumprido: o de gerar desenvolvimento sustentável (DS) para o meio rural, considerando que não fica claro o que a CCGL entende por DS. Neste trabalho adota-se a noção de desenvolvimento sustentável abordada por Veiga $(2000 ; 2005)$. Este autor defende uma concepção de desenvolvimento que vai além do crescimento econômico, pois abrange as variáveis sociais, econômicas, ambientais e culturais, princípios estes que coincidem com a concepção de desenvolvimento sustentável.

O que parece ter faltado nesse processo é uma organização por parte dos agricultores, na busca de uma avaliação das informações repassadas pela CCGL, bem como do futuro da atividade leiteira na região. Isso poderia ter sido feito pela FETAG, porém, esta não possuía informações "privilegiadas" a ponto de indicar as melhores saídas para o agricultor e/ou indicar cautela em suas ações. As informações que a entidade representante da classe obtinha eram escassas e até distorcida, pois, como afirma Downing (2002), torna-se até ingenuidade se pensarmos que a cultura e a comunicação são coisas democráticas, mesmo quando construídas de forma organizada, pois os processos e diferenciais de poder estão presentes em toda parte.

A CCGL apresentou sua proposta e buscou envolver o agricultor em sua causa, lhes dando garantias (em forma de palavras) que não foram cumpridas após a colaboração desses 
agricultores. Ou seja, por um lado os agricultores "abraçaram a causa" e aumentaram a produção de leite, porém, a CCGL não cumpriu sua parte que era a garantia de lucratividade e ações para o desenvolvimento rural sustentável.

Além destas questões, há ainda a problemática ambiental, que foi praticamente esquecida no processo em tela. Ainda na década de 1980, Morin (1984) já alertava que um processo de desenvolvimento deveria prever a diminuição dos impactos e da pressão sobre os recursos naturais, caso contrário se caracterizaria como crescimento econômico apenas. Sachs (1995) também contribui nesse sentido ao ressaltar a importância do aproveitamento dos recursos naturais sem destruir o "capital da natureza". Complementa destacando que o desenvolvimento deveria seguir uma hierarquização: o social no comando, o ecológico enquanto restrição assumida e o econômico como papel instrumental.

As propriedades rurais em questão adotam, significativamente, o sistema produtivo de bovinocultura de leite intensivo, especialmente pelo fato das propriedades terem áreas pequenas (inviabilizando e/ou dificultando a eficiência de outros sistemas de produção, p.e., leite a pasto) e por optarem em não abandonar as outras atividades produtivas que exigem parte significativa da propriedade (ex: soja e trigo). Este sistema é altamente exigente em insumos e tecnologia e também é poluente, em especial pelo volume de resíduos que gera (esterco e urina) por área, suscitando a possibilidade de contaminação do solo e água (mananciais e lençol freático). O poder público, as entidades, o setor privado e parte dos agricultores têm conhecimento dos problemas ambientais que causa a atividade, porém, não foram tomadas medidas significativas para a redução das chamadas externalidades negativas ${ }^{7}$.

Observa-se, portanto, que o processo instalado na região levanta alguns problemas sociais, ambientais, econômicos e culturais. Porém, considera-se importante a instalação de um processo de fortalecimento de estratégias que incentivem a ação social conjunta, o acesso igualitário às ações do poder público municipal, o respeito e a preservação dos recursos naturais, bem como o respeito à cultura local. Além disso, torna-se fundamental que os agricultores tenham acesso ao conhecimento técnico e de mercado da atividade para que os recursos sejam empregados com cautela. Yruela e Guerrero (1994) apontam o desenvolvimento local como uma opção na busca de abandonar a passividade e iniciar um esforço no sentido de aproveitar os recursos disponíveis e empregá-los na geração de emprego e riqueza nas localidades. Para os autores, o enfoque local para o desenvolvimento deve contar com os conhecimentos e experiências existentes, bem como deve considerar a possibilidade de criar em nível local o clima social necessário, baseado na articulação social.

\section{Considerações finais}

O presente trabalho, que buscou descrever e analisar criticamente um processo de mobilização social relacionado ao meio rural, demonstrou como estas ações podem trazer questões negativas para o setor. Como observado, dos três objetivos pregados pela CCGL (aumento de produção, de lucratividade e geração de desenvolvimento rural), apenas um deles foi alcançado com sucesso, que foi o aumento da produção.

\footnotetext{
${ }^{7}$ As externalidades também são chamadas de economias ou deseconomias externas, cujos efeitos podem ser positivos ou negativos - em termos de custos ou de benefícios - gerados pelas atividades de produção ou consumo exercidas por um agente econômico e que atingem os demais agentes, sem que haja incentivos. No caso do estudo, as externalidades negativas dizem respeito aos impactos, geralmente negativos, decorrentes da atividade leiteira junto ao meio ambiente.
} 
Porém, ao alcançar esse objetivo, alguns problemas foram gerados, principalmente relacionados a viabilidade econômica da produção. Isso ocorreu pelo acréscimo de investimentos na atividade de bovinocultura de leite, por parte dos agricultores, seguida por uma queda significativa no preço recebido pelo produto.

Os objetivos referentes ao desenvolvimento rural ficaram distantes de ser alcançados, visto que se considerou desenvolvimento o processo que inclui aspectos não só econômicos, mas também ambientais, culturais e sociais. Porém, as conseqüências mais concretas desse processo aparecerão com mais força no ano de 2010, quando a maioria dos empréstimos feitos pelos agricultores começa a vencer e precisarão ser pagos. Embora seja um problema financeiro que estará por vir, pode ter conseqüências nos demais condicionantes do desenvolvimento, visto que problemas econômicos limitam outras questões, sendo um aspecto extremamente valorizado pelos produtores rurais.

O que pôde ser observado, é que esse processo se constituiu numa ação estratégica das empresas com objetivos claros de ampliarem seus lucros. Uma das principais fragilidades da estratégia analisada é a falta de interação e colaboração entre os agricultores. Para que essas interações ocorram, deve haver mecanismos para ativá-las e estimulá-las, permitindo que aconteçam de modo organizado e contribuam para um novo processo social, no qual as oportunidades se apresentem igualmente a todos os atores. No momento que os agricultores deixaram que essas iniciativas fossem construídas sem uma ação grupal na localidade, se permitiu que os grupos mais fortes e organizados (empresa processadora) se apropriassem em maior medida dos benefícios.

Essa análise crítica alerta para discursos falsos. Para a necessidade de não confiar plenamente nas cooperativas de produtores rurais, as quais nem sempre estarão, de fato, defendendo os interesses dos agricultores. Também, demonstra a necessidade do fortalecimento das bases dos agricultores, especialmente do Sindicato dos Trabalhadores Rurais, que precisa estar atento às informações na busca de alertar os agricultores em momentos delicados como o descrito nesse trabalho.

\section{Referências}

BAITELLO JUNIOR, N. A mídia primária, secundária e terciária. In: Anais do IX Encontro Anual da Associação Nacional dos Programas de Pós-Graduação em Comunicaçãa-COMPOS. Porto Alegre, 2000.

BOUDON, R. Dicionário crítico de sociologia. São Paulo: Ática, 1992.

BOHMAN. J. La democracia deliberativa y sus críticos. Metapolítica, Ciudad de México, v. 4, n. 14, p. 48-57, abr.-jun.2000.

BREITENBACH, R. Estruturas de mercado de fatores e governança na cadeia produtiva do leite: um estudo de caso no município de Ajuricaba - RS. 2008. Dissertação (Mestrado em Extensão Rural) - Universidade Federal de Santa Maria. Santa Maria, 2008.

BREITENBACH, R. et al. Estratégia emergencial reativa de desenvolvimento local: mobilização social para intensificação da produção leiteira. In: Revista Desenvolvimento em Questão. Ano 7, nº 13, jan/jun. Ijuí : Ed Unijuí, 2009. 
COOPERATIVA CENTRAL GAÚCHA LTDA. www.ccgl.com.br Notícias acessadas em: 26, 27 e 28 de Outubro de 2008.

COOPERATIVA REGIONAL TRITÍCOLA SERRANA. www.cotrijui.coop.br Notícias acessadas em: 26, 27 e 28 de Outubro de 2008.

DOWNING, J. D. Mídia radical: rebeldia nas comunicações e movimentos sociais. São Paulo; Editora SENAC São Paulo, 2002.

ESCOBAR, A. Encountering Development. New Jersey: Princeton University Press. 1995.

GUERRERO, M. G. La red social como elemento clave del desarrollo local. Lisboa: Sociedade Portuguesa de Estudos Rurais, 1996.

MAFRA, R. Entre o espetáculo, a festa e a argumentação - mídia, comunicação estratégica e mobilização social. Belo Horizonte: Autêntica, 2006.

MARCONI, M. de A.; LAKATOS, E. M. Fundamentos de Metodologia Científica $5^{\mathrm{a} e d .}$ Atlas. São Paulo - SP, 2003.

MORIN, E. Sociologia. Lisboa: Publicações Europa-América. 1984.

PROSS, H. Medienforschung. Darmstadt: Carl Habel, 1971.

QUIJANO, A. Colonialidade do Poder, Eurocentrismo e América Latina. In: LANDER, Edgardo. A Colonialidade do Saber - Eurocentrismo e Ciências Sociais / Perspectivas Latino-Americanas. CLACSO. Argentina, 2005.

RÁDIO PROGRESSO DE IJUÍ. www.rpi.com.br Notícias acessadas em: 26, 27 e 28 de Outubro de 2008.

SACHS. I. Em busca de novas estratégias de desenvolvimento. In: Estudos Avançados. V. 9, n.25. São Paulo: Edusp. 1995.

SANTOS, A. R. dos. Metodologia Científica - a construção do conhecimento. $7^{\text {aed. }}$ Lamparina. Rio de Janeiro - RJ, 2007.

SCHNEIDER, S. Agricultura familiar e desenvolvimento rural endógeno: elementos teóricos e estudo de caso. In: FROHELICH, J. M.; DIESEL, V. (Orgs.). Desenvolvimento rural: tendências e debates contemporâneos. Ijuí. Ed: Unijuí, 2006.

SOUZA, M. L. A teorização sobre o desenvolvimento em uma época de fadiga teórica, ou: sobre a necessidade de uma Teoria Aberta do desenvolvimento sócio espacial. In: Território. Rio de Janeiro: LAGET-UFRJ/Garamont. n. 3. Jul-Dez 1996.

SOUZA, M. L. Algumas notas sobre a importância do espaço para o desenvolvimento social. In: Território. Rio de Janeiro: LAGET-UFRJ/Garamont. n. 3. Jul-Dez 1997.

TÉVOÉDJRÈ, Albert. A Pobreza, Riqueza dos Povos - a transformação pela solidariedade. Tradução de Reinaldo Matias Fleuri. 3ªed. Vozes. Petrópolis - RJ, 1978/2002.

TUCKER, V. A cultural perspective on development. In: The European Journal of Development Research. London: Frank Cass e Co. Ltd., v. 8, n.2, 1996.

VEIGA, J. E. da. A face rural do desenvolvimento: natureza, território e agricultura. Porto Alegre: Ed. UFRGS, 2000.

.O prelúdio do desenvolvimento sustentável. Disponível em: $<$ http://www.econ.fea.usp.br/zeeli> Acesso em: 10 de out. de 2006. 
VIANA, J. G. A. et. al. Comportamento dos Preços Históricos do Leite no Rio Grande do Sul, Brasil. Ciênc. agrotec., Lavras, v. 34, n. 2, p. 451-460, mar./abr., 2010.

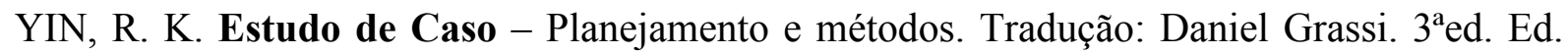
Bookman. Porto Alegre - RS, 2005.

YRUELA, M. P. E GUERRERO, M. G. Desarrollo local y desarrollo rural: el contexto Del programa 'Leader'. In: Papeles de Economia Española. N. 60-61, pp. 219-233, 1994.

ZANELA, M. B. et. al. Qualidade do Leite em Sistemas de Produção na Região Sul do Rio Grande do Sul. Pesquisa agropecuária brasileira. Brasília, v.41, n.1, p.153-159, jan. 2006. 